\title{
Proses Penuaan (Aging) pada Paduan Aluminium AA 333 Hasil Proses Sand Casting
}

\author{
Anne Zulfia ${ }^{1}$, Ratna Juwita ${ }^{1}$, Ari Uliana ${ }^{1}$, I Nyoman Jujur² dan Jarot Raharjo ${ }^{2}$ \\ ${ }^{1}$ Departemen Metalurgi dan Material, Fakultas Teknik Universitas Indonesia, Jakarta \\ ${ }^{2}$ Pusat Pengembangan Penelitian Teknologi Material (P3TM) BPPT, Jakarta \\ E-mail: anne@metal.ui.ac.id
}

\begin{abstract}
ABSTRAK
Penggunaan paduan aluminium AA 333 sebagai komponen otomotif semakin berkembang bersamaan dengan semakin berkembangnya keinginan untuk mengurangi berat dari komponen yang digunakan. Namun paduan aluminium AA 333 as-cast masih memiliki sifat mekanis yang rendah sehingga diperlukan proses lain untuk meningkatkan kekerasannya, salah satunya melalui proses perlakuan panas. Proses perlakuan panas yang dipilih dalam penelitian ini adalah proses perlakuan panas T6 (artificial aging), yang meliputi tahapan: solution treatment pada temperatur $525^{\circ} \mathrm{C}$ selama 8 jam, quenching dan proses aging. Variabel yang digunakan dalam penelitian ini adalah variasi waktu aging (temperatur $180^{\circ} \mathrm{C}$ ), yaitu 25 menit, 1 jam, 5 jam, 8 jam dan $16 \mathrm{jam}$ dan variasi temperatur aging (waktu aging $5 \mathrm{jam}$ ), yaitu $110^{\circ} \mathrm{C}, 150^{\circ} \mathrm{C}$, $180^{\circ} \mathrm{C}, 200^{\circ} \mathrm{C}, 250^{\circ} \mathrm{C}$. Dari penelitian ini diharapkan dapat diketahui pengaruh dari variasi tersebut terhadap perubahan struktur mikro dan nilai kekerasan paduan aluminium AA 333. Hasil penelitian menunjukkan bahwa aging temperatur $180^{\circ} \mathrm{C}$ menyebabkan peningkatan kekerasan dari tiap fase: matrik a-Al, silikon primer, eutektik $\mathrm{Al}_{-} \mathrm{Al}_{2} \mathrm{Cu}$ dan $\mathrm{Al}_{15}(\mathrm{Fe}, \mathrm{Mn})_{3} \mathrm{Si}_{2}$ dan menyebabkan peningkatan kekerasan paduan aluminium AA 333, dari kondisi as-cast, asquench, dan waktu aging 25 menit, 1 jam, 5 jam, 8 jam dan 16 jam. Hasil penelitian lainnya juga menunjukkan bahwa proses aging selama 5 jam juga menyebabkan peningkatan kekerasan dari tiap fase. Waktu aging (pada temperatur $180^{\circ} \mathrm{C}$ ) selama 8 jam dan temperatur aging (selama 5 jam) pada $180^{\circ} \mathrm{C}$ merupakan waktu yang paling optimum untuk memperoleh kombinasi yang terbaik dari distribusi fase, yang tersebar merata dalam matrik kaya $\mathrm{Al}$, dan ukuran dari masing-masing fase sehingga menghasilkan nilai kekerasan yang tertinggi.
\end{abstract}

Kata kunci: Aluminium AA333, penuaan buatan (T6), kekerasan, struktur mikro.

\begin{abstract}
The use of aluminum alloys $A A 333$ as automotive component is progressively expand with the expanding desire to lose weight from the used component. However, the as-cast product from aluminum alloys AA 333 is still having low mechanical properties, so it needs the other process to increase the hardness value; one of the processes is through heat treatment process. The heat treatment process for this materials is T6 process (artificial aging), including: solution treatment at temperature $525^{\circ} \mathrm{C}$ for 8 hour, quenching and various time of aging process. Aging was conducted at $180^{\circ} \mathrm{C}$ for 25 minutes, 1 hours, 5 hours, 8 hours and 16 hours respectively. For aging 5 hours, the aging temperature was applied various from $110^{\circ} \mathrm{C}, 150^{\circ} \mathrm{C}, 180^{\circ} \mathrm{C}, 200^{\circ} \mathrm{C}$ to $250^{\circ} \mathrm{C}$, so the expected result from this research is to know the influence of the variation to morphological change of microstructure and hardness value of aluminum alloys $A A$ 333. The results had indicated that the aging process at $180^{\circ} \mathrm{C}$ caused the increased of the hardness value of each phases: $a$-Al matrix, primary silicon, eutectic $\mathrm{Al}-\mathrm{Al} \mathrm{C}_{2} \mathrm{Cu}$ and $\mathrm{Al}_{15}(\mathrm{Fe}, \mathrm{Mn})_{3} \mathrm{Si}_{2}$ and also caused the increased of the hardness value of aluminum alloys $A A 333$, from the condition of as-cast, as-quench, aging process for 25 minutes, 1 hours, 5 hours, 8 hours and 16 hours. And others results had indicated that the aging process for 5 hours also caused increasing of hardness value of each phases. The aging process $\left(a t 180^{\circ} \mathrm{C}\right)$ for 8 hours and 5 hours) represented the most optimum time to obtained the best combination from phase distribution, that spread over in the rich matrix of aluminum and the size measured from each phase, therefore giving the highest hardness value.
\end{abstract}

Keywords: Aluminium AA333, articial aging (T6), hardness, microstructure. 


\section{PENDAHULUAN}

Aluminium dan paduannya merupakan jenis material yang cukup penting dikarenakan nilai teknologinya yang tinggi dan aplikasinya yang luas. Dalam industri otomotif, permasalahan seputar pemakaian bahan bakar dan pengurangan berat dari komponen yang digunakan, telah membuat penggunaan paduan aluminium dalam industri ini semakin berkembang. Dengan mengurangi berat dari komponen yang digunakan maka konsumsi energi dalam hal pengunaan bahan bakar dan emisi gas buangannya juga dapat dikurangi [1]. Paduan aluminium memiliki densitas yang rendah yaitu 2,7 $\mathrm{g} / \mathrm{cm}^{3}$. Dengan densitas yang rendah, penggunaan aluminium sebagai komponen otomotif dapat mereduksi berat keseluruhan kendaraan lebih dari 300 $\mathrm{kg}$ untuk kendaraan berukuran medium $(1400 \mathrm{~kg})$. Dimana setiap pengurangan berat sebesar $100 \mathrm{~kg}$, akan mengurangi konsumsi bahan bakar yang diperlukan sebesar 0.3-0.6 liter per $100 \mathrm{~km}$ sehingga dapat menurunkan emisi gas buangan sebanyak 20\% [1]. Dari berbagai jenis paduan aluminium, paduan aluminium $\mathrm{Al}-\mathrm{Si}-\mathrm{Cu}$ merupakan paduan yang paling umum digunakan dalam industri otomotif. Dalam beberapa tahun belakangan ini, penggunaan paduan aluminium tersebut meningkat, terutama di industri otomotif yang menggunakan secondary aluminum hasil recycling dalam bentuk berbagai komponen seperti piston, cylinder head, wheel, load floor suspension [2], crank case dan manifold [3]. Namun paduan Al-Si-Cu hasil pengecoran masih memiliki sifat mekanis yang rendah [4] sehingga diperlukan proses lain untuk meningkatkan kekuatannya. Salah satu caranya yaitu melalui proses perlakuan panas.

Proses perlakuan panas tersebut bertujuan untuk mengubah struktur mikro paduan sehingga sifat mekaniknya dapat berubah. Dalam penelitian ini proses perlakuan panas yang dipilih adalah proses perlakuan panas T6 yang meliputi proses solution heat treating, quenching dan proses artificial aging. Proses artificial aging umumnya dilakukan pada temperatur rendah dan dalam waktu yang cukup lama, bervariasi antara 5-48 jam [5]. Pemilihan dalam jangka waktu berapa proses tersebut seharusnya dilakukan haruslah diperhitungkan secara cermat. Hal itu disebabkan karena waktu dilakukannya proses aging dapat menyebabkan perbedaan pada jenis, fraksi volume, ukuran dan distribusi partikel endapan, yang pada akhirnya dapat mempengaruhi struktur akhir dan menghasilkan sifat mekanik yang berbeda [5]. Zhang $\mathrm{dkk}[6]$ mendemonstrasikan bahwa $\mathrm{Al}-\mathrm{Si}-\mathrm{Mg}$ dengan solution treatment pada suhu $540^{\circ} \mathrm{C}$ selama 10 menit dan setelah beberapa jam maka dicapai kekuatan tarik puncak $90 \%$. Kenaikan waktu tahan solution treatment sampai 30 menit maka cukup waktu untuk mikrostruktur berubah mencapai nilai elongasi 90\%. Paduan yang sama Shykumar dkk [7] mengatakan bahwa kenaikan temperatur solution treatment akan mengurangi waktu tahan menurutnya untuk mencapai puncak kekuatann tarik maka dengan solution treatment pada suhu $550^{\circ} \mathrm{C}$ hanya perlu waktu tahan 50 menit. Solution heat treatment terdiri dari tiga langkah: solution, quenching, dan aging. Perubahan mikrostruktur terjadi karena tahapan solution treatment meliputi proses quenching dan aging. Penguatan endapan dari paduan Al-Si$\mathrm{Mg}$ adalah adanya fase $\mathrm{Mg}_{2} \mathrm{Si}$ yang terjadi pada saat peleburan $\mathrm{Al}$ kemudian dengan kecepatan pendinginan yang lama pada saat solidifikasi terbentuklah endapan $\mathrm{Mg}_{2} \mathrm{Si}$. Bila dilakukan proses saat solution treatment maka tumbuh endapan inkoheren didalam matrik $\mathrm{Al}$ menjadi endapan yang lebih halus sehingga kekuatan meningkat. Endapan $\mathrm{Mg}_{2} \mathrm{Si}$ yang halus terdispersi di dalam matrik $\mathrm{Al}$ pada saat solution treatment. Solution treatment pada temperature $540^{\circ} \mathrm{C}, \mathrm{Mg}_{2} \mathrm{Si}$ larut kembali kedalam matrik $\mathrm{Al}$ dan juga fase $\mathrm{Si}$ berubah dari bentuk berupa pelat ke bentuk bulat yang meningkatkan keuletan dari paduan.

Pada proses aging, unsur-unsur paduan dalam solid solution secara bertahap keluar dan membentuk presipitat yang dapat meningkatkan kekuatan paduan. Mekanisme penguatan terjadi melalui precipitate shearing dan dislocation bypass (orowan looping). Dalam precipitate shearing, dislokasi bergerak melewati presipitat dengan memotong presipitat tersebut. Mekanisme ini umumnya terjadi pada partikel yang mudah terdeformasi yaitu pada presipitat yang berukuran kecil. Sedangkan pada dislocation bypass, dislokasi dapat melewati partikel dengan cara melengkung pada ruang di antara presipitat dan meninggalkan dislocation loop disekitar presipitat tersebut. Mekanisme ini umumnya terjadi pada presipitat yang sulit dideformasi dan berukuran besar sedangkan mekanisme penguatan yang dihasilkan oleh presipitat tergantung pada dua faktor yaitu ukuran partikel dan jarak antar partikel [8]. Partikelpartikel kecil yang terdispersi merata pada awal proses pengerasan presipitat, tidak memberikan efek penguatan yang efektif bagi paduan karena partikel tersebut bukan merupakan penghalang yang kuat bagi pergerakan dislokasi. Partikelpartikel besar yang terdispersi secara acak pada waktu pengerasan presipitat yang lama juga tidak memberikan efek penguatan yang efektif. Hal ini disebabkan karena pada partikel besar, jarak antar partikelnya juga besar, sehingga dislokasi dapat dengan mudah bergerak melalui mekanisme orowan looping [8]. Umumnya kekuatan paduan akan meningkat dengan peningkatan ukuran partikel selama dislokasi dapat memotong partikel. Jika dislokasi dapat melewati partikel melalui orowan looping, peningkatan ukuran partikel akan menurunkan kekuatan paduan, seperti yang diilustrasikan pada Gambar 1. 


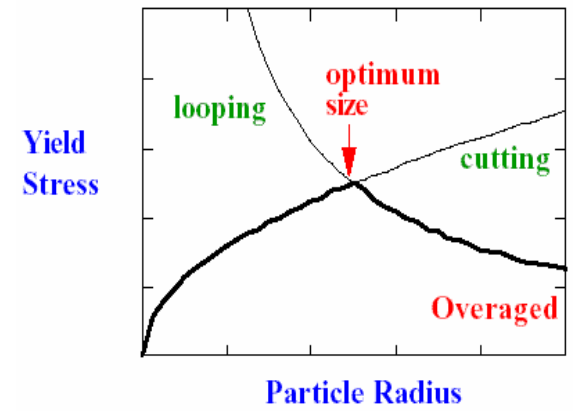

Gambar 1. Pengaruh Ukuran Partikel pada Peningkatan Kekuatan Paduan [9]

Tabel 1. Komposisi Kimia Paduan Aluminum AA 333 dalam \% Berat

\begin{tabular}{ccccccccccc}
$\mathrm{Si}$ & $\mathrm{Cu}$ & $\mathrm{Mg}$ & $\mathrm{Fe}$ & $\mathrm{Mn}$ & $\mathrm{Zn}$ & $\mathrm{Ti}$ & $\mathrm{Pb}$ & $\mathrm{Ni}$ & $\mathrm{Cr}$ & $\mathrm{Sn}$ \\
\hline 8,00 & 2,35 & - & 0,79 & 0,26 & 0,71 & 0,03 & 0,05 & 0,13 & 0,02 & 0,02 \\
\hline
\end{tabular}

\section{METODE PENELITIAN}

\section{Bahan dan Proses Perlakuan Panas}

Bahan yang dipergunakan dalam penelitian ini adalah paduan aluminium AA 333 hasil proses sand casting. Adapun komposisi paduan aluminum AA 333 yang digunakan adalah seperti yang terlihat pada Tabel 1.

Sebelum proses pengamatan metalografi dan pengujian kekerasan dilakukan, benda uji terlebih dahulu mengalami proses perlakuan panas T6 yang meliputi tahapan: solution treatment pada temperatur $525^{\circ} \mathrm{C}$ selama 8 jam, quenching dan proses aging yang dilakukan dua bagian, bagian pertama pada temperatur $180^{\circ} \mathrm{C}$ dengan variabel waktu aging yaitu 25 menit, 1 jam, 5 jam, 8 jam dan 16 jam dan bagian kedua selama 5 jam dengan variabel temperatur yaitu $110^{\circ} \mathrm{C}, 150^{\circ} \mathrm{C}, 180^{\circ} \mathrm{C}, 200^{\circ} \mathrm{C}, 250^{\circ} \mathrm{C}$. Proses solution treatment dilakukan di dapur pemanas tipe Carbolyte pada temperatur $525^{\circ} \mathrm{C}$ selama 8 jam. Kemudian sampel di-quench di media air dan selanjutnya dilakukan proses aging di dapur pemanas tipe Nabetherm pada temperatur $180^{\circ} \mathrm{C}$ selama 25 menit, 1 jam, 5 jam, 8 jam dan 16 jam. Sampel yang digunakan untuk pengamatan metalografi dan pengujian kekerasan terlebih dulu di-mounting dengan menggunakan resin yang dikeraskan dengan hardener. Selanjutnya dilakukan proses pengamplasan dan pemolesan dan diakhiri dengan proses etsa dengan menggunakan zat etsa berupa larutan HF 0.5\%.

\section{Karakterisasi}

Karakterisasi benda uji yang dilakukan meliputi pengujian kekerasan dengan menggunakan dua metode pengujian yaitu pengujian kekerasan Brinell dan pengujian Microhardness. Keduannya memiliki prinsip yang sama yaitu pemberian beban kepada permukaan sampel dengan menggunakan indentor sehingga dihasilkan jejak. Jejak yang terbentuk kemudian diukur. Sedangkan untuk mengamati karakteristik fase-fase yang terbentuk, dilakukanlah proses pengamatan mikrostruktur dengan menggunakan mikroskop optik Olympus yang dilengkapi kamera digital dan dengan SEM (Scanning Electron Microscope) LEO 420 yang dilengkapi dengan EDS (Energy-Dispersive Spectroscopy). EDS sendiri digunakan untuk pengamatan komposisi dari fase-fase yang terdapat pada paduan aluminium AA 333, sehingga data yang dihasilkan dapat digunakan untuk mendukung data pengamatan mikrostruktur yang dilakukan dengan mikroskop optik dan SEM.

\section{HASIL DAN PEMBAHASAN}

\section{Karakteristik Paduan Aluminium pada Kondisi as-cast}

Struktur mikro dari paduan aluminium AA 333 as-cast, ditunjukkan pada Gambar 2 di bawah ini, menunjukkan struktur mikro dari paduan aluminium AA 333 as-cast, yang terdiri dari matrik yang merupakan fase yang dominan dan struktur interdenditik yang merupakan ciri khas paduan aluminium hasil pengecoran.

Fase-fase yang terbentuk yang dimati dengan SEM yang dikaitkan dengan EDS hasilnya ditunjukkan dalam Tabel 2. Hasil analisa EDS untuk paduan aluminium AA 333 as-cast mengindikasikan terbentuknya fase-fase: matriks kaya akan $\mathrm{Al}$, eutektik $\mathrm{Al}-\mathrm{Al}_{2} \mathrm{Cu}, \mathrm{Al}_{x}(\mathrm{Fe}, \mathrm{Mn})_{y} \mathrm{Si}_{\mathrm{z}}$ dan kristal silikon.

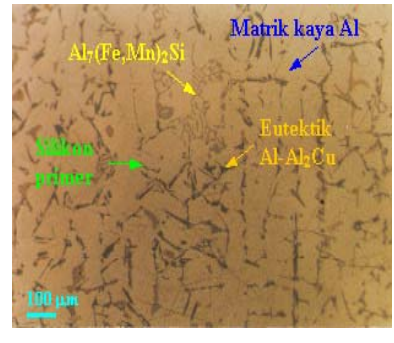

(a) Foto Mikro, Pembesaran 100x

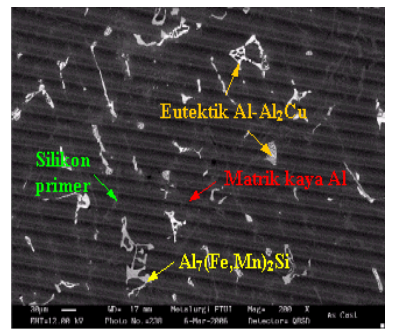

(b) Foto Hasil Pengujian SEM, Pembesaran 200x
Gambar 2. Foto Struktur Mikro dan SEM Paduan Aluminium AA 333 as-cast

Tabel 2. Hasil Analisa Komposisi Paduan Aluminium AA 333 As-cast Menggunakan EDS

\begin{tabular}{|c|c|c|c|c|c|c|c|}
\hline \multicolumn{6}{|c|}{ Komposisi (\% berat) } & \multirow{2}{*}{ Morfologi } & \multirow{2}{*}{$\begin{array}{c}\text { Indikasi Fasa yang } \\
\text { Terbentuk }\end{array}$} \\
\hline $\mathrm{Al}$ & $\mathrm{Si}$ & $\mathrm{Fe}$ & $\mathrm{Cu}$ & $\mathrm{Mn}$ & $\mathrm{Cr}$ & & \\
\hline 96,28 & 2,16 & - & - & - & 1,55 & - & $\alpha-\mathrm{Al}$ \\
\hline 67,92 & 6,22 & - & 11,03 & - & 14,84 & Chinesse script & $\mathrm{Al}-\mathrm{Al}_{2} \mathrm{Cu}$ Eutektik \\
\hline 52,85 & 9,86 & 27,47 & 0,92 & 3,90 & 5,00 & Chinesse script & $\mathrm{Al}_{\mathrm{x}}(\mathrm{FeMn})_{\mathrm{y}} \mathrm{Si}_{\mathrm{z}}$ \\
\hline 5,93 & 94,07 & - & - & - & - & Needle & Kristal silikon \\
\hline
\end{tabular}


Tabel 3 dan 4 memperlihatkan nilai kekerasan pada paduan aluminium AA 333 as-cast hasil pengujian dengan metode Vickers dan Brinell. Perbedaan nilai kekerasan antara paduan aluminium AA 333 hasil pengujian dengan standar pada Tabel 3 disebabkan karena perbedaan laju pendinginan dan porositas yang dikandung oleh paduan aluminium AA 333 as cast. Persentase porositas pada paduan yang menggunakan cetakan pasir cenderung lebih tinggi daripada permanent mold. Tingkat porositas yang lebih tinggi dan ukuran porositas yang lebih besar ini terbentuk akibat koagulasi dari porositas mikro dan tingginya tingkat penyerapan hidrogen dan air oleh leburan saat didalam cetakan pasir [10]. Oleh karena itu nilai kekerasan paduan aluminium AA 333 yang menggunakan cetakan pasir lebih rendah dari paduan aluminium AA standar yang menggunakan permanent mould.

\section{Karakteristik Paduan Aluminium pada Kondisi Setelah Proses Aging Pengaruh Waktu Aging}

Struktur mikro paduan aluminium AA 333 selama proses perlakuan panas T6 (artificial aging) pada temperatur $180^{\circ} \mathrm{C}$ ditunjukkan pada Gambar 3 hingga Gambar 8 yang menunjukkan perubahan ukuran dan bentuk dari fase-fase yang terdapat pada paduan aluminium AA 333 setelah perlakuan panas T6.

Tabel 3. Nilai Kekerasan Tiap-tiap Fase Paduan Aluminium AA 333 As-cast

\begin{tabular}{cc}
\hline Fase & Kekerasan $(\mathrm{VHN})^{*}$ \\
\hline $\mathrm{a}-\mathrm{Al}$ & 39 \\
$\mathrm{Silikon}$ primer & 46 \\
$\mathrm{Al}_{7}(\mathrm{Fe}, \mathrm{Mn})_{2} \mathrm{Si}$ & 159 \\
$\mathrm{Al}_{2} \mathrm{Cu}$ & 88
\end{tabular}

* Merupakan nilai kekerasan mikro Vickers yang didapat dengan pembebanan sebesar $25 \mathrm{kgf}(245,15 \mathrm{~N})$

Tabel 4. Nilai Kekerasan Brinell Paduan Aluminium AA 333 As-cast Dibandingkan dengan Standar Paduan Aluminium AA 333 As-cast

\begin{tabular}{lcc}
\hline \multirow{2}{*}{ Material } & \multicolumn{2}{c}{ Kekerasan } \\
\cline { 2 - 3 } & Brinell (BHN) & Vickers (VHN) \\
\hline $\begin{array}{l}\text { Paduan AA 333 } \\
\text { As-cast }\end{array}$ & $53^{\text {(a) }}$ & 75 \\
$\begin{array}{l}\text { Paduan AA 333 } \\
\text { As-cast standar }\end{array}$ & $90^{\text {(b) }}$ & 102 \\
\hline Catatan: &
\end{tabular}

\section{Catatan:}

(a) Merupakan nilai kekerasan Brinell yang didapat dengan menggunakan bola baja berdiameter 2,5 $\mathrm{mm}$ dan pembebanan sebesar 31,25 kgf (306,5 N) selama 30 detik

(b) Merupakan nilai kekerasan Brinell yang didapat dengan menggunakan bola baja berdiameter $10 \mathrm{~mm}$ dan pembebanan sebesar $500 \mathrm{kgf}(4903 \mathrm{~N}$ )

(c) Merupakan hasil konversi dari nilai kekerasan Brinell

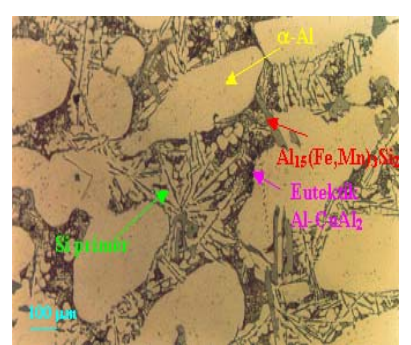

a. As-quench

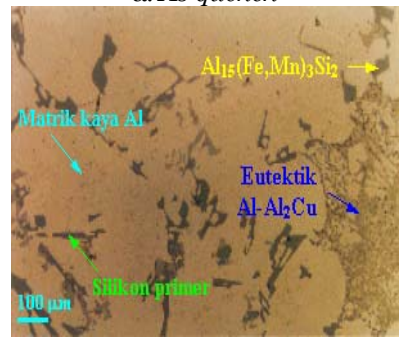

c. Aging Selama 1 Jam

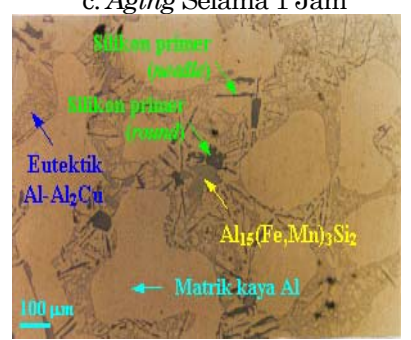

e. Aging Selama 8 Jam

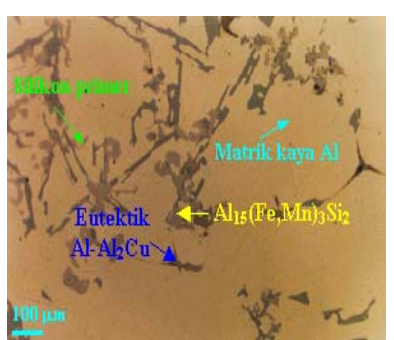

b. Aging Selama 25 Menit

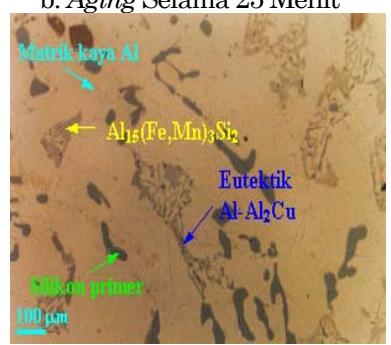

d. Aging Selama 5 Jam

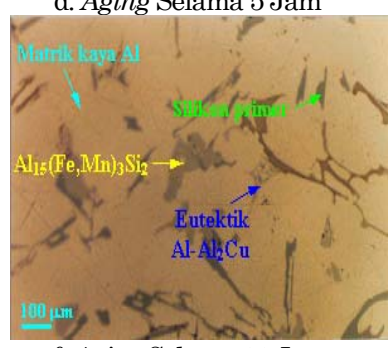

f. Aging Selama 16 Jam
Gambar 3. Mikrostruktur dari Paduan Aluminium A333 pada Perbesaran 100X

Gambar 3 menunjukkan perubahan morfologi dendritik seiring dengan peningkatan waktu aging yaitu terjadinya perubahan morfologi dalam bentuk pengkasaran fase, yang merupakan fenomena yang umum terjadi pada tahap akhir dari evolusi struktur mikro[11]. Dengan meningkatnya waktu aging pada temperatur tertentu, dalam hal ini $180^{\circ} \mathrm{C}$, akan menyebabkan fase yang berukuran lebih kecil, akan larut dan berdifusi kedalam matrik a-Al[12]. Partikel dari fase kedua yang lebih besar, cenderung untuk terus tumbuh saat proses pengkasaran fase dengan cara atom-atom terlarut pada matrik disekelilingnya (lihat Tabel 5 dan 6). Semakin lama, suatu difusi yang disebut "competitive diffusion" terjadi dan menghasilkan peningkatan ukuran ratarata dari partikel fase kedua tersebut, namun diiringi dengan penurunan jumlah partikel[11].

Tabel 5. Hasil Analisa Komposisi Paduan Aluminium AA 333 As-quench Dengan Menggunakan EDS

\begin{tabular}{|c|c|c|c|c|c|c|c|}
\hline \multicolumn{6}{|c|}{ Komposisi (\% berat) } & \multirow{2}{*}{ Morfologi } & \multirow{2}{*}{$\begin{array}{c}\text { Indikasi Fasa yang } \\
\text { Terbentuk }\end{array}$} \\
\hline $\mathrm{Al}$ & $\mathrm{Si}$ & $\mathrm{Fe}$ & $\mathrm{Cu}$ & $\mathrm{Mn}$ & $\mathrm{Cr}$ & & \\
\hline 97,67 & 2,33 & - & - & - & - & - & $\alpha-A l$ \\
\hline 84,42 & 8,05 & - & 7,53 & - & - & Chinesse script & $\mathrm{Al}-\mathrm{Al}_{2} \mathrm{Cu}$ Eutektik \\
\hline 51,79 & 8,94 & 17,12 & 0,92 & 21,07 & 1,10 & Blocky & $\mathrm{Al}_{\mathrm{x}}(\mathrm{FeMn})_{\mathrm{y}} \mathrm{Si}_{\mathrm{z}}$ \\
\hline 1,90 & 98,10 & - & - & - & - & Needle & Si primer \\
\hline 0,25 & 99,75 & - & - & - & - & blocky & Si primer \\
\hline
\end{tabular}


Tabel 6. Hasil Analisa Komposisi Paduan Aluminium AA 333 Setelah Proses Aging Selama 8 Jam Menggunakan EDS

\begin{tabular}{|c|c|c|c|c|c|c|c|}
\hline \multicolumn{6}{|c|}{ Komposisi (\% berat) } & \multirow{2}{*}{ Morfologi } & \multirow{2}{*}{$\begin{array}{c}\text { Indikasi Fasa yang } \\
\text { Terbentuk }\end{array}$} \\
\hline $\mathrm{Al}$ & $\mathrm{Si}$ & $\mathrm{Fe}$ & $\mathrm{Cu}$ & $\mathrm{Mn}$ & $\mathrm{Cr}$ & & \\
\hline 97,67 & 2,33 & - & - & - & - & - & \\
\hline 84,42 & 8,05 & - & 7,53 & - & - & Chinesse script & $\mathrm{Al}-\mathrm{Al}_{2} \mathrm{Cu}$ Eutektik \\
\hline 51,79 & 8,94 & 17,12 & 0,92 & 21,07 & 1,10 & Blocky & $\mathrm{Al}_{\mathrm{x}}(\mathrm{FeMn})_{\mathrm{y}} \mathrm{Si}_{\mathrm{z}}$ \\
\hline 1,90 & 98,10 & - & - & - & - & Needle & Si primer \\
\hline 0,25 & 99,75 & - & - & - & - & blocky & Si primer \\
\hline
\end{tabular}

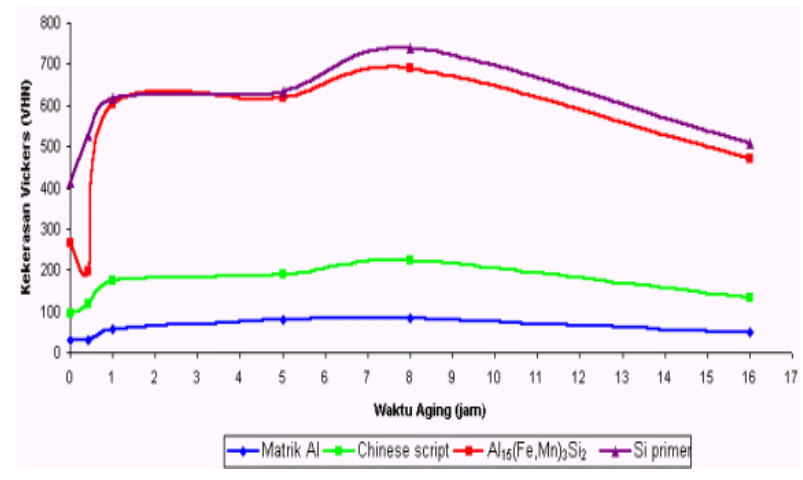

Gambar 4. Kekerasan Tiap Fase Setelah Pengerasan Presipitat Pada Temperatur $180^{\circ} \mathrm{C}$

Melalui perbandingan struktur mikro paduan aluminium AA 333 setelah proses perlakuan panas seperti pada Gambar 3 diketahui bahwa proses aging pada temperatur $180^{\circ} \mathrm{C}$ telah merubah struktur mikro dari paduan aluminium AA 333 as-cast. Partikel silikon primer yang berbentuk jarum menunjukan perubahan bentuk spheroidizing, dimulai dari kondisi aging 1 jam, 5 jam dan yang paling optimum terjadi pada kondisi aging 8 jam. Perubahan morfologi inilah yang menyebabkan kekerasan Brinell dan kekerasan partikel silikon meningkat seiring dengan semakin lama waktu aging sampai pada titik optimal yaitu pada kondisi aging 8 jam. Pengujian mengenai proses modifikasi dari bentuk partikel silikon melalui perlakuan panas yang dapat meningkatkan sifat mekanis yang meliputi nilai kekerasannya, sehingga memperbaiki kualitas operasional dari paduan tersebut [13].

Selain disebabkan oleh partikel silikon primer, peningkatan nilai kekerasan Brinell juga disebabkan oleh fase-fase lainnya, diantaranya adalah fase $\mathrm{Al}_{2} \mathrm{Cu}$. Dimulai dari kondisi aging 1 jam sampai pada kondisi aging 8 jam, terjadi peningkatan kekerasan. Hal ini juga disebabkan karena terjadinya perubahan bentuk dari fase $\mathrm{Al}_{2} \mathrm{Cu}$ dari struktur chinese script berukuran kecil menjadi ukuran besar dan saling terkait antara satu fase dengan fase lainnya. Perubahan ini dapat meningkatkan sifat mekanis seperti nilai kekerasannya [12]. Oleh karena itu, pada kondisi aging 1 jam, 5 jam dan 8 jam, nilai kekerasan Brinell dan kekerasan fasenya meningkat. Namun pada kondisi aging 25 menit, nilai kekerasan fase eutektik $\mathrm{Al}-\mathrm{Al}_{2} \mathrm{Cu}$ justru meningkat.

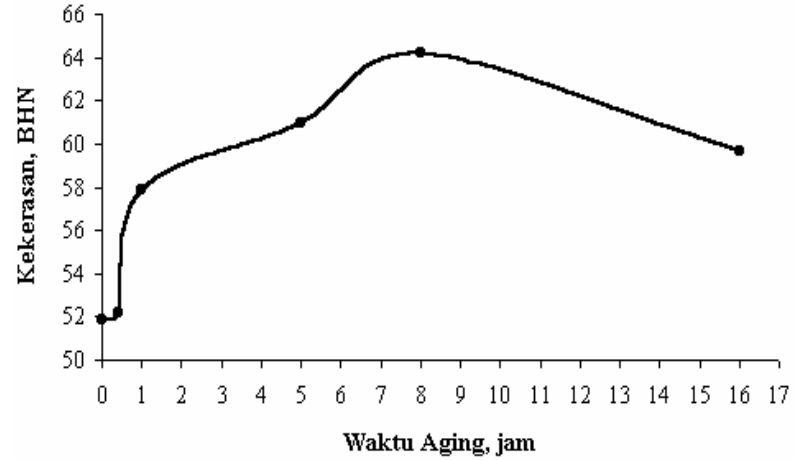

Gambar 5. Pengerasan Presipitat Paduan Aluminium AA 333 pada Temperatur $1^{\circ} 0^{\circ} \mathrm{C}$

Hal berlawanan dengan apa yang dijelaskan di atas, bahwa peningkatan nilai kekerasan disebabkan karena peningkatan ukuran dari fase eutektik Al$\mathrm{Al}_{2} \mathrm{Cu}$ tersebut. Peningkatan kekerasan pada waktu aging 25 menit ini kemungkinan dipengaruhi oleh kandungan fase eutektik $\mathrm{Al}-\mathrm{Al}_{2} \mathrm{Cu}$. Melalui pengamatan dengan menggunakan EDS, diketahui bahwa fase eutektik $\mathrm{Al}-\mathrm{Al}_{2} \mathrm{Cu}$ pada kondisi 25 menit mengandung unsur $\mathrm{Fe}, \mathrm{Si}, \mathrm{Ni}$ dan $\mathrm{Cu}$. Unsur pengkotor inilah yang memberikan kontribusi terhadap peningkatan kekerasan dari fase eutektik $\mathrm{Al}-\mathrm{Al}_{2} \mathrm{Cu}$ dan juga peningkatan kekerasan Brinell pada kondisi aging 25 menit (Gambar 4).

Fase $\mathrm{Al}_{15}(\mathrm{Fe}, \mathrm{Mn})_{3} \mathrm{Si}_{2}$ juga turut memberikan kontribusi terhadap peningkatan nilai kekerasan paduan aluminium AA 333. Pada Gambar 3 hingga 8, diketahui perbandingan struktur mikro setelah proses perlakuan panas. Pada kondisi aging 25 menit, fase $\mathrm{Al}_{15}(\mathrm{Fe}, \mathrm{Mn})_{3} \mathrm{Si}_{2}$ berbentuk polihedral dengan ukuran yang kecil dan dalam jumlah yang tidak terlalu banyak. Hal ini menyebabkan nilai kekerasan fase ini menurun pada kondisi aging 25 menit. Dengan semakin lama proses aging, yaitu dari kondisi aging 1 jam, 5 jam dan 8 jam, ukuran fase $\mathrm{Al}_{7}(\mathrm{Fe}, \mathrm{Mn})_{2} \mathrm{Si}$ semakin membesar dan bentuknya pun berubah menjadi lebih bulat tanpa adanya sudut yang tajam. Peningkatan nilai kekerasan dari fase $\mathrm{Al}_{15}(\mathrm{Fe}, \mathrm{Mn})_{3} \mathrm{Si}_{2}$ selama proses perlakuan panas memberikan kontribusi terhadap peningkatan kekerasan fase $\mathrm{Al}_{15}(\mathrm{Fe}, \mathrm{Mn})_{3} \mathrm{Si}_{2}$, sampai pada kondisi optimum yaitu proses aging selama 8 jam (Gambar 3).

Dengan peningkatan kekerasan dari hampir semua fase penyusun paduan aluminium AA 333 maka hal tersebut memberikan kontribusi terhadap peningkatan kekerasan Brinell, seperti ditunjukkan pada kurva pengerasan presipitat pada Gambar 5 . Peningkatan kekerasan disebabkan karena terjadinya mekanisme penguatan akibat terhambatnya pergerakan dislokasi oleh partikel fase. Mekanisme pengerasan yang dihasilkan oleh proses pengkasaran fase kedua tergantung pada dua faktor yaitu ukuran partikel dan jarak antar partikel [13]. 
Partikel-partikel kecil yang terdispersi merata pada awal proses pengerasan presipitat, pada kondisi aging 25 menit, tidak memberikan efek penguatan yang efektif bagi paduan karena partikel tersebut bukan merupakan penghalang yang kuat bagi pergerakan dislokasi. Partikel-partikel besar yang terdispersi secara acak pada waktu pengerasan presipitat yang lama, pada kondisi aging 16 jam, juga tidak memberikan efek penguatan yang efektif juga. Hal ini disebabkan karena pada partikel besar, jarak antar partikelnya juga besar. sehingga dislokasi dapat dengan mudah bergerak melalui mekanisme orowan looping.

Umumnya nilai kekerasan akan meningkat dengan peningkatan ukuran partikel, selama dislokasi dapat memotong partikel. Jika dislokasi dapat melewati partikel melalui orowan looping, peningkatan ukuran partikel akan menurunkan kekuatan paduan, seperti yang diilustrasikan pada Gambar 6. Hal ini menunjukkan bahwa kondisi penguatan yang optimum tercapai bila presipitat yang terbentuk memiliki ukuran yang cukup besar namun jarak antar partikel yang rapat (terdispersi secara merata) sehingga dapat memberikan hambatan yang maksimum terhadap pergerakan dislokasi. Hal inilah yang terjadi pada kondisi aging 8 jam (Gambar 3), yang merupakan kondisi aging paling optimum dimana fase-fase yang terbentuk memiliki ukuran yang optimum dan tersebar merata dalam matrik kaya $\mathrm{Al}$ sehingga menghasilkan nilai kekerasan paduan aluminium AA 333 yang paling tinggi.

\section{Pengaruh Temperatur Aging}

Struktur mikro paduan aluminium AA 333 selama proses perlakuan panas T6 (artificial aging) selama 5 jam ditunjukkan pada Gambar 7, yang menunjukkan perubahan ukuran dan bentuk dari fase-fase yang terdapat pada paduan aluminium AA 333 setelah perlakuan panas T6.

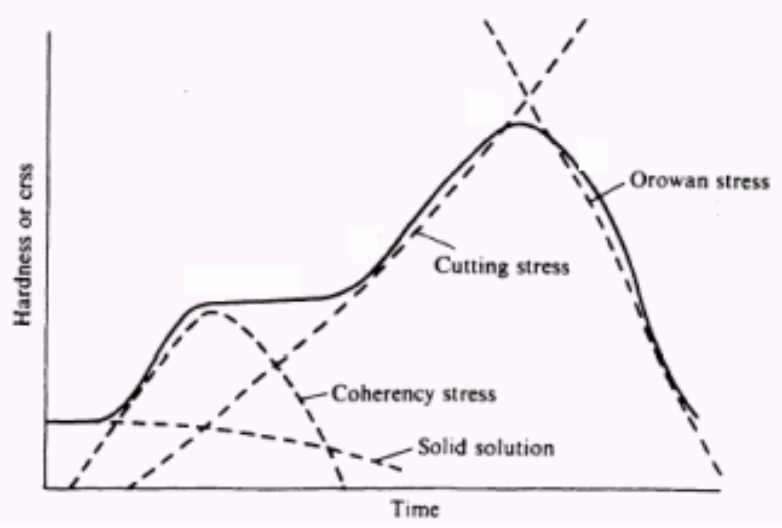

Gambar 6. Pengaruh dari Penguatan pada Kekerasan dalam Kurva Pengerasan Presipitat [14]
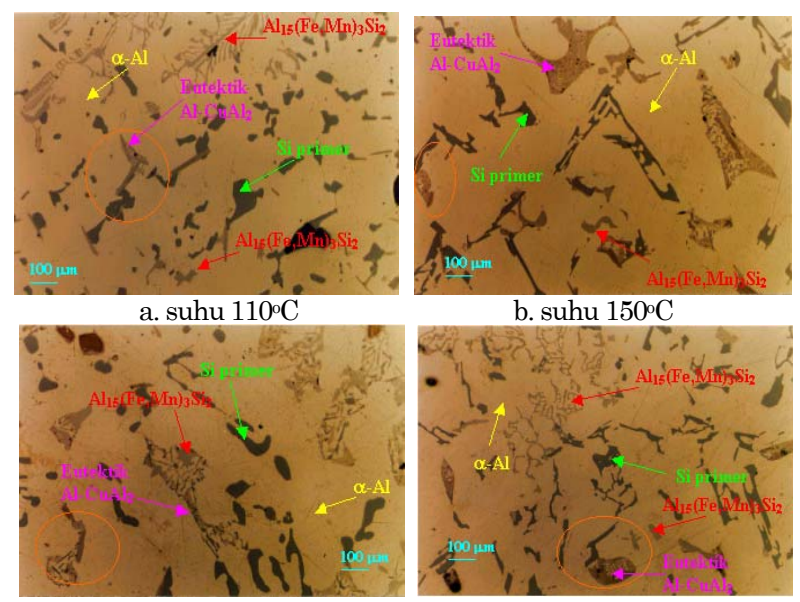

b. suhu $150^{\circ} \mathrm{C}$

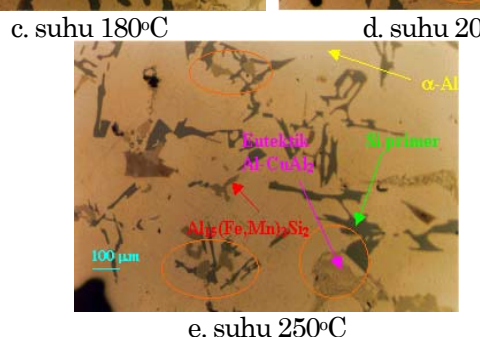

e. suhu $250^{\circ} \mathrm{C}$

Gambar 7. Mikrostruktur paduan Aluminium AA 333 setelah aging selama 5 jam, pada suhu berbeda pada Pembesaran 100X

Tabel 7. Hasil analisa komposisi paduan aluminium AA 333 aging $180^{\circ} \mathrm{C}$ selama 5 jam dengan menggunakan EDS

\begin{tabular}{|c|c|c|c|c|c|c|}
\hline \multirow{2}{*}{$\begin{array}{c}\text { Indikasi Fasa yang } \\
\text { terbentuk }\end{array}$} & \multicolumn{5}{|c|}{ Komposisi (\% berat) } & \multirow{2}{*}{ Morfologi } \\
\hline & $\mathrm{A} 1$ & $\mathrm{Si}$ & $\mathrm{Cu}$ & $\mathrm{Fe} \quad \mathrm{Mn}$ & $\mathrm{Ni}$ & \\
\hline Silikon primer & 0,17 & 98,83 & - & - & - & Block \\
\hline $\mathrm{Al}_{15}(\mathrm{Mn}, \mathrm{Fe})_{3} \mathrm{Si}_{2}$ & 52,08 & 9,27 & - & $16,5422,10$ & - & Block \\
\hline $\mathrm{CuAl}_{2} \& \mathrm{Cu}_{2} \mathrm{FeAl}_{7}$ & 76,94 & 8,04 & 7,87 & 3,50 & $-3,65$ & Chinese script \\
\hline$\alpha-\mathrm{Al}$ & 98,01 & 1,99 & - & - & - & - \\
\hline
\end{tabular}

Gambar 7 menunjukkan perubahan morfologi fase-fase yang terdapat pada paduan aluminium AA 333 setelah perlakuan aging selama 5 jam dan hasil EDS pada Tabel 7 untuk aging $180^{\circ} \mathrm{C}$. Morfologi fase silikon berturut-turut berubah dari yang bentuk jarum yang terikat pada interdendritik as-quench kemudian selama aging $110^{\circ} \mathrm{C}$ jarum tersebut menebal dan memisahkan diri dari interdendritik. Peningkatan temperatur ke $150^{\circ} \mathrm{C}$ menghasilkan fase silikon yang berbentuk flakes (lebih tebal dari jarum) sehingga kekerasannya menurun, keadaan ini berbeda ketika temperatur meningkat menjadi $180^{\circ} \mathrm{C}$, fase silikon berubah menjadi lebih tebal lagi dan cenderung spheroid dari sebelum dan sesudahnya sehingga kekerasan fase silikon pada aging ini merupakan kekerasan silikon tertinggi. Aging $200^{\circ} \mathrm{C}$, fase silikon mulai ada yang melarut dan mulai menjadi flakes kembali seperti pada aging $150^{\circ} \mathrm{C}$ tetapi masih terdapat bentuk blocky sehingga kekerasan fase ini lebih tinggi dari fase silikon pada aging $150^{\circ} \mathrm{C}$. Temperatur aging $250^{\circ} \mathrm{C}$ cukup tinggi untuk membuat fase-fase silikon banyak yang melarut, ditandai dengan penampakan daerah matriks yang lebih luas dan kekerasan fase ini mencapai titik terendah (Gambar 8). 


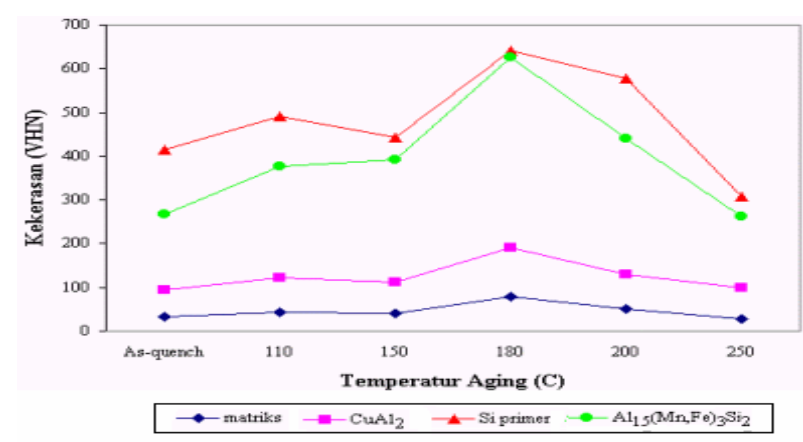

Gambar 8. Kekerasan Setiap Fase Paduan Aluminium AA 333 Setelah Perlakuan Panas Selama 5 Jam
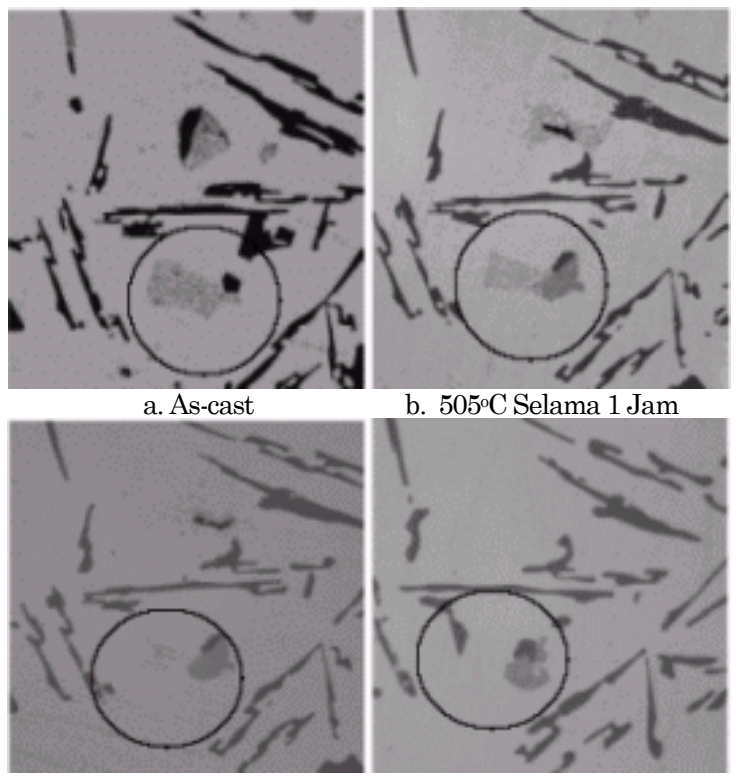

b. $505^{\circ} \mathrm{C}$ Selama $1 \mathrm{Jam}$

c, $505^{\circ} \mathrm{C}$ Selama $2 \mathrm{Jam}$

d. $505^{\circ} \mathrm{C}$ Selama 8 Jam

Gambar 9. Perubahan Morfologi Fase Eutektik Berasal dari Lokasi yang Sama[17]

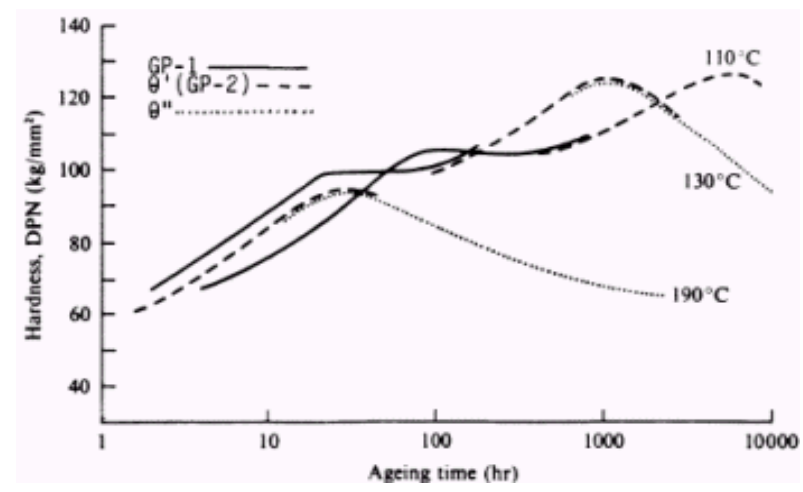

Gambar 10. Penguatan Presipitasi Al-4Cu: Kekerasan dan Struktur Presipitat terhadap Waktu pada Berbagai Temperatur. (Solution Treated: $540^{\circ} \mathrm{C}$ untuk 2 hari)[18]

Fase $\mathrm{Al}_{15}(\mathrm{Mn}, \mathrm{Fe})_{3} \mathrm{Si}_{2}$ mempunyai morfologi yang berbeda-beda di setiap perlakuan. Morfologi ini dipengaruhi oleh kandungan $\mathrm{Mn}$. Untuk kandungan Mn yang rendah, fase $\mathrm{Al}_{15}(\mathrm{Mn}, \mathrm{Fe})_{3} \mathrm{Si}_{2}$ ini akan membentuk chinese script[15], sedangkan, ketika kandungan $\mathrm{Mn}$ tinggi fase $\mathrm{Al}_{15}(\mathrm{Mn}, \mathrm{Fe})_{3} \mathrm{Si}_{2}$ akan membentuk blocky [16] seperti pada Gambar 9. Fase $\mathrm{CuAl}_{2}$ berpresipitasi dalam dua morfologi: eutektik $\mathrm{Al}-\mathrm{CuAl}_{2}$ dan dalam bentuk blocky dengan konsentrasi $\mathrm{Cu}$ yang tinggi ( $38-40 \%$ berat). Selama pembekuan dendritik, fase $\mathrm{CuAl}_{2}$ tumbuh secara bersama-sama dengan aAl dengan morfologi yang sama seperti paduan biner yang bebas dari keberadaan Si. Morfologi $\mathrm{CuAl}_{2}$ yang ada di berbagai temperatur aging memperlihatkan bentuk chinese script, dibuktikan dengan kandungan $\mathrm{Cu}$ yang rendah (8,89\% berat pada as-quench dan 7,87\% berat pada temperatur aging $180^{\circ} \mathrm{C}$ ) [17].

Temperatur aging $180^{\circ} \mathrm{C}$ mencapai puncak selama 8 jam[18], sedangkan untuk temperatur aging $200^{\circ} \mathrm{C}$ bila dibandingkan dengan Gambar 10 belum mencapai puncak, begitu pula pada aging $110^{\circ} \mathrm{C}$ dan $150^{\circ} \mathrm{C}$ sesuai dengan literatur pada Gambar 10, dimana untuk temperatur aging yang rendah $110^{\circ} \mathrm{C}$ dan $130^{\circ} \mathrm{C}$ pencapaian puncak kekerasan memakan waktu yang cukup lama. Jadi pada waktu aging 5 jam belum cukup untuk mencapai kekerasan tertinggi. Kekerasan paduan aluminium AA 333 meningkat hingga mencapai puncaknya pada aging $180^{\circ} \mathrm{C}$ kemudian turun hingga kekerasan yang sangat rendah pada aging $250^{\circ} \mathrm{C}$ disebabkan presipitat yang terkandung telah terlarut kembali akibat temperatur yang tinggi.

\section{KESIMPULAN}

Dari hasil penelitian mengenai pengaruh temperatur aging pada paduan aluminium AA 333 diperoleh kesimpulan bahwa peningkatan temperatur aging hingga $180^{\circ} \mathrm{C}$ selama 5 jam dapat meningkatkan kekerasan as-quench dari 73,538 VHN menjadi 80,925 VHN. Ketika temperatur terus ditingkatkan hingga $250^{\circ} \mathrm{C}$ dengan waktu aging yang tetap, kekerasannya menurun kembali hingga 60,933 VHN, hal ini berkaitan pula dengan fase yang terbentuk pada paduan aluminium AA 333 asquench yang mempunyai morfologi struktur interdendritik terdiri dari: silikon primer, $\mathrm{Al}_{15}(\mathrm{Mn}, \mathrm{Fe})_{3} \mathrm{Si}_{2}, \mathrm{Al}_{-} \mathrm{CuAl}_{2}$ (eutektik) dan aAl. Fase silikon primer mempunyai morfologi needle. Kandungan Mn yang cukup tinggi sebesar 21,07\% wt membentuk blocky pada fase $\mathrm{Al}_{15}(\mathrm{Mn}, \mathrm{Fe})_{3} \mathrm{Si}_{2}$. Morfologi chinese script pada fase eutektik $\mathrm{Al}-\mathrm{CuAl}_{2}$ dibentuk oleh kandungan $\mathrm{Cu}$ yang rendah sebesar $8,59 \%$ wt. Fase silikon primer mempunyai kekerasan tertinggi sebesar $641,35 \mathrm{VHN}$ pada paduan aluminium AA 333 di semua variasi temperatur aging selama 5 jam dan kekerasan presipitasi $\mathrm{CuAl}_{2}$ pada temperatur aging $110^{\circ} \mathrm{C}, 150^{\circ} \mathrm{C}, 180^{\circ} \mathrm{C}$, dan $200^{\circ} \mathrm{C}$ selama 5 jam belum mencapai kekerasan tertinggi. Sedangkan pada temperatur aging $250^{\circ} \mathrm{C}$ selama 5 jam telah melewati kekerasan tertingginya. 


\section{DAFTAR PUSTAKA}

1. Aluminum Alloys: Aluminum Usage in The Transportation Industry, (online), http://www.azom.com/ details.asp?ArticleID=1964 diakses 7 Maret 2006.

2. Rios, C. Triveno dan Caram, R., 2003. Intermetallic Compound in The Al-Si-Cu System, (online), http://www.sbmm.org.br/actar/trabalhos/ 14.pdf diakses 28 Februari 2006.

3. JIS Handbook. Non-Ferrous Metals and Metallurgy. Japanese Standards Association. 1978.

4. Altenpohl, D., Aluminum Viewed from Within. Aluminum-Verlag GmbH. German. 1982.

5. ASM Handbook. Volume 4. Heat Treating. ASM International. USA. 1991.

6. D. Zhang, L. Zheng, and D. St. John, Effect of a Short Solution Treatment Time on Microstructure and Mechanical Properties of Modifi ed Al7wt.\% Si- 0.3wt.\%Mg Alloy, Journal of Light Metals, 2, pp. 27-36, 2002.

7. S. Shivkumar et al., Influence of Solution Treatment on Tensile Properties of Sr Modifi ed Al-Si-Mg Alloys, Journal of Heat Treating, 8, pp. 63-70, 1990.

6. Strenghtening Mechanism, (online), http://www. tu-darmstadt.de/fb/ms/student/fs/german/lab/w6/ mse6-3.htm\#Precipitate diakses 18 Februai 2006.

7. Obstacles to Dislocation Motion, (online), http:// www.poco.phy.cam.ac.uk/teaching/A_Donald/ Crystalline_Solids_2.pdf diakses 18 februari 2006.

8. Warmuzek, M dan Ratuszek, W., 2004, Chemical Inhomogeneity of Intermetallic Phases Precipitates Formed During Solidification of Al-Si Alloy, (online), http://www.elsevier.co.id diakses 18 Februari 2006.

9. ASM Handbook. Aluminum and Aluminum Alloys. ASM International. USA. 1997.

10. Mangonon, Pat L., The Principles of Materials Selection for Engineering Design, Prentice-Hall, Inc., USA, 1999.
11. Ringer S P dan K, Hono, Microstructure Evolution and Age Hardening in Aluminum Alloys: Atom Probe Field-Ion Microscopy and Transmission Electron Microscopy Studies, (online), http://www.elsevier.co.id/Journal.pdf di akses 10 Februari 2006.

12. Wyatt, O.H., dan Hughes, Dew, D., Metals, Ceramic and Polymer, Cambridge University Press. 1974.

13. Dinnis, Cameron M. As-cast Morphology of IronIntermetallics in Al-Si Foundry Alloys. Scripta Materialia. University of Queenslands, Australia. 2005. (online), www.scincedirect.com diakses 10 Februari 2006.

14. Dinnis, Cameron M. As-cast Morphology of IronIntermetallics in Al-Si Foundry Alloys. Scripta Materialia. University of Queenslands, Australia. 2005. (online), www.scincedirect.com diakses 10 Februari 2006.

15. Qian, M. dkk. Solute Redistribution during Solution Treatment of Cast Al-Si-Cu-Mg-Fe Alloys. Institute of Materials Scince, University of Connecticut. (online), http://www.engr.uconn. edu/ qianmin/Paper/ASM-Soln2.pdf diakses 15 Maret 2006.

16. Meier, Mike. Heat Treatments of Aluminum Alloys. Department of Chemical Engineering and Materials Science, University of California, September 13, 2004. (online), www.matsci. ucdavis. edu/MatSciLT/Other/Files/HT-Aluminum.pdf di akses 15 Februari 2006.

17. Qian, M. dkk. Solute Redistribution during Solution Treatment of Cast Al-Si-Cu-Mg-Fe Alloys. Institute of Materials Scince, University of Connecticut. (online), (http://www.engr.uconn.edu/ qianmin/ Paper/ASM-Soln2.pdf diakses 15 Maret 2006)

18. Meier, Mike. Heat Treatments of Aluminum Alloys. Department of Chemical Engineering and Materials Science, University of California, September 13, 2004. (online), (www.matsci. ucdavis.edu/MatSciLT/Other/Files/HT-Aluminum. pdf diakses 15 Februari 2006). 